\title{
Abstração Refletida no Processo de Gênese Instrumental em Ambiente 3D
}

\author{
Abstractions Reflected in the Process of Instrumental \\ Genesis in 3D Environment
}

Margarete Farias Medeiros
IFC/UFRGS

Marcus Basso

UFRGS

Resumo: Apresenta-se o recorte de uma pesquisa qualitativa e exploratória em curso sob a forma de estudo de caso. Investiga-se a apropriação do GeoGebra 3D pelo estudante de licenciatura em matemática. Tem-se como objetivo identificar uma conexão entre a Abstração Refletida e o processo de Gênese Instrumental do sujeito a partir da observação de condutas cognitivas em duas etapas: numa oficina instrumentada em ambiente 3D e numa de simulação de atividade docente neste mesmo ambiente. Cria-se um modelo para a conexão entre as duas teorias. Considera-se que o sujeito se apropriou do ambiente 3D quando tomou consciência das características do ambiente: dependência funcional geométrica; variação dinâmica para destacar a invariância geométrica; compreensão da limitação do ambiente estático do lápis e papel em relação ao ambiente dinâmico. Ao realizar as tarefas no ambiente e simular atividade docente, concluiu-se que o estudante realizou abstrações refletidas sobre o seu processo de gênese instrumental.

Palavras-chave: Abstração Refletida. Gênese Instrumental. Ambiente 3D.

\begin{abstract}
The clipping of a qualitative and exploratory research is presented in the form of a case study. The appropriation of GeoGebra 3D by the mathematics degree student is investigated. It aims to identify a connection between reflected abstraction and the process of instrumental genesis of the subject from the observation of cognitive behaviors in two stages: in a workshop instrumented in a 3D environment and in one simulation of teaching activity in this same environment. A model is created for the connection between the two theories. It is considered that the subject appropriated the 3D environment when he became aware of the characteristics of the environment: geometric functional dependence; dynamic variation to highlight geometric invariance; understanding of the limitation of the static environment of the pencil and paper in relation to the dynamic environment. When performing the tasks in the environment and simulating teaching activity, it was concluded that the student performed abstractions reflected on his process of the instrumental genesis.
\end{abstract}

Keywords: Reflected Abstraction. Instrumental Genesis. 3D environment. 


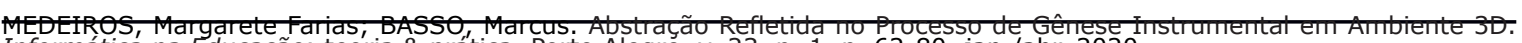
Informáticá na Educação: teoria \& prática, Porto Alegre, v. 23, n. 1, p. 62-80, jan./abr. 2020. 


\section{Introdução}

As pesquisas sobre a inserção da Tecnologia Digital (TD) na sala de aula (BONA, FAGUNDES e BASSO, 2012; SILVA, BARONE e BASSO, 2014; ABAR, 2017; ALQAHTANI e POWELL, 2017; ROCK, 2017; RUIZ-LÓPEZ, 2017; BACKENDORF e BASSO, 2018; NOTARE e BASSO, 2018) apontam as vantagens para a aprendizagem da matemática.

Pondera-se que o professor deve se utilizar de tais recursos para propiciar a aprendizagem; entretanto, a inserção da TD na prática docente depende da concepção do professor de matemática e da sua apropriação tecnológica, a qual pode ser apresentada sob a forma de resistência a sua inserção. Haspekian (2013) mostra que existem razões mais profundas para a resistência dos professores, sendo estas relacionadas ao impacto que a TD tem sobre a matemática a ser ensinada e a dificuldade, para os professores, na gestão desse impacto. Diante dessas considerações, entende-se que, se existe certa resistência por parte dos professores de matemática nessa inserção tecnológica, poder-se-ia diminuí-la, intervindo-se na formação inicial destes.

Este artigo apresenta um estudo de caso, no qual se investiga a apropriação tecnológica do GeoGebra1 3D por um licenciando em matemática. O estudo é parte de uma pesquisa em curso na qual estão sendo analisadas as condutas cognitivas e tarefas de cinco estudantes. Optou-se por expor resultados parciais de um desses casos, considerado como um caso exemplar por ter apresentado resultados positivos na primeira intervenção.

Para amparar o estudo, buscou-se apoio no mecanismo da Abstração Reflexionante e na teoria da Gênese Instrumental. Estabeleceu-se uma conexão entre a Abstração Refletida (PIAGET, 1995) e o processo de Gênese Instrumental (RABARDEL, 1995) do sujeito, quando submetido a uma sequência de tarefas no ambiente 3D e na simulação da função docente neste mesmo ambiente. Criou-se um modelo conectando a abstração refletida com o processo de gênese instrumental, propondo-se investigar o processo de abstração reflexionante, mais especificamente da abstração refletida, com tomada de consciência, quando o sujeito transforma o artefato em instrumento na construção de conceitos de geometria espacial.

$\mathrm{Na}$ seção que segue, expõe-se o quadro teórico caracterizando: o processo de gênese instrumental do sujeito; o mecanismo da abstração reflexionante, bem como estudos relacionados, os quais utilizaram-se deste mecanismo na Educação Matemática; a abstração refletida no processo de gênese instrumental.

Nas seções seguintes são destacados os objetivos e a metodologia. Nos resultados e discussões são exibidas as análises do caso em questão: das tarefas no GeoGebra 3D; das escritas do estudante; da conduta cognitiva na oficina instrumentada; da entrevista via formulário; da conduta na oficina de simulação de atividade docente e da entrevista inspirada no método clínico. Dando seguimento, apresentam-se as considerações finais sobre o estudo realizado.

\section{Quadro Teórico}

\footnotetext{
1 geogebra.org.br
} 
Utiliza-se o quadro teórico fornecido pela abordagem instrumental (RABARDEL, 1995), OS incrementos de TROUCHE (2000, 2003), os quais propõem ampliar o escopo desta abordagem, geralmente dedicada ao uso da TD e da atividade profissional dos professores. Além disso, a exposição do mecanismo da Abstração Reflexionante (PIAGET,1995) constitui-se importante na medida que traduz a teoria da equilibração, possibilitando entender a tomada de consciência e, por esta, compreender o processo de abstração refletida do sujeito por ocasião das apropriações tecnológicas. Nas subseções seguintes, exibe-se uma breve explanação deste quadro teórico com exemplos de tarefas realizadas no ambiente 3D.

\subsection{De um Artefato a um Instrumento}

Rabardel (1995), no campo da ergonomia cognitiva, a partir das ideias tanto de Piaget quanto de Vygotsky, apresentou a abordagem instrumental como importante teoria para compreender a apropriação tecnológica, fazendo a distinção entre artefato e instrumento. Ele propôs um modelo chamado S.A.I. (Situations d'Activités Instrumentées) (figura 1), mostrando as diferentes interações entre sujeito, instrumento e objeto.

Figura 1 - Modelo S.A.I.

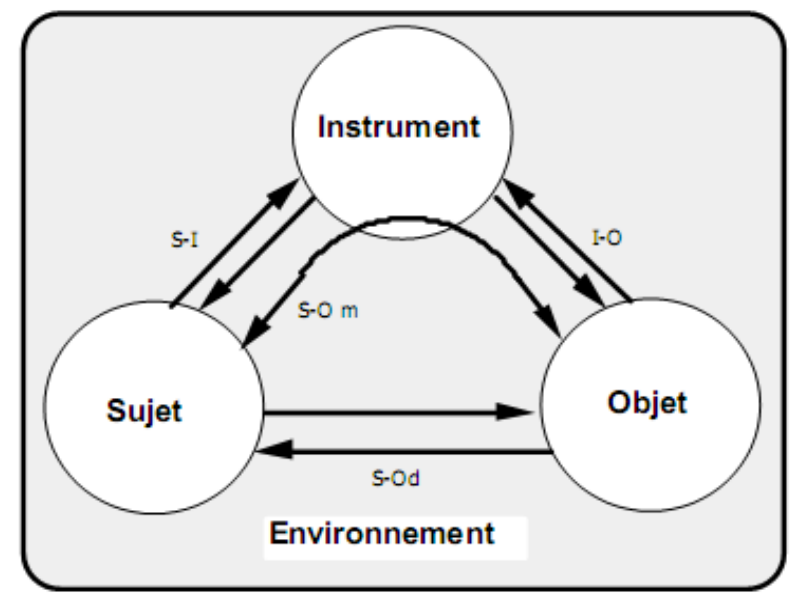

Fonte: Rabardel (1995, p. 53)

Segundo Curth (2015): "Um modelo na ciência é o resultado do processo de geração de uma representação abstrata para uma parte da realidade, seja esta um objeto, um fenômeno, um processo, um sistema ou qualquer outra coisa de interesse." Nesse modelo (figura 1), Rabardel (1995, p.53) representa o processo de gênese instrumental: "com este modelo ternário mostra-se a multiplicidade e complexidade de relações e as interações entre os diferentes polos $(\ldots)^{\prime \prime}$, o sujeito, o instrumento e o objeto.

Para Abar e Alencar (2013, p. 353), esse modelo (figura 1) "evidencia as várias interações que intervêm nas atividades instrumentais: sujeito-objeto [S-O], sujeito-instrumento [S-I], instrumento-objeto [I-O] e sujeito-objeto mediada pelo instrumento [S(I)-O] (...)", as quais são desenvolvidas em um ambiente composto pelo conjunto de requisitos que o sujeito precisa considerar para fazer uma tarefa. 
No que segue, mostram-se desdobramentos dessa teoria, na concepção de autores embasados em Rabardel (1995), os quais conceituam sujeito, instrumento e objeto, bem como situações em que serão exemplificadas as interações entre eles.

Drijvers e Trouche (2008) definem artefato como um objeto material ou não: um computador é um artefato material, e a linguagem matemática é um artefato abstrato; sendo que ambos são produzidos para a atividade humana. Para realizar essa atividade humana, o sujeito acrescenta a esse artefato um esquema (VERGNAUD, 1996), tem-se então a formação de um instrumento, uma entidade mista formada de artefato mais o esquema criado pelo sujeito (Rabardel, 1995). Essa transformação de artefato em instrumento é chamada por Rabardel (1995) de gênese instrumental (figura 1) formada por dois componentes: a instrumentação (orientada para o sujeito) e a instrumentalização (orientada para o artefato).

Maschietto e Trouche (2009) expõem o modelo (figura 2) embasado em Rabardel (1995), no qual esse processo de gênese instrumental ocorre mediante a realização de uma tarefa específica, sendo que o sujeito poderá utilizar-se apenas de uma parte do artefato no decorrer de um período.

Figura 2 - Gênese Instrumental

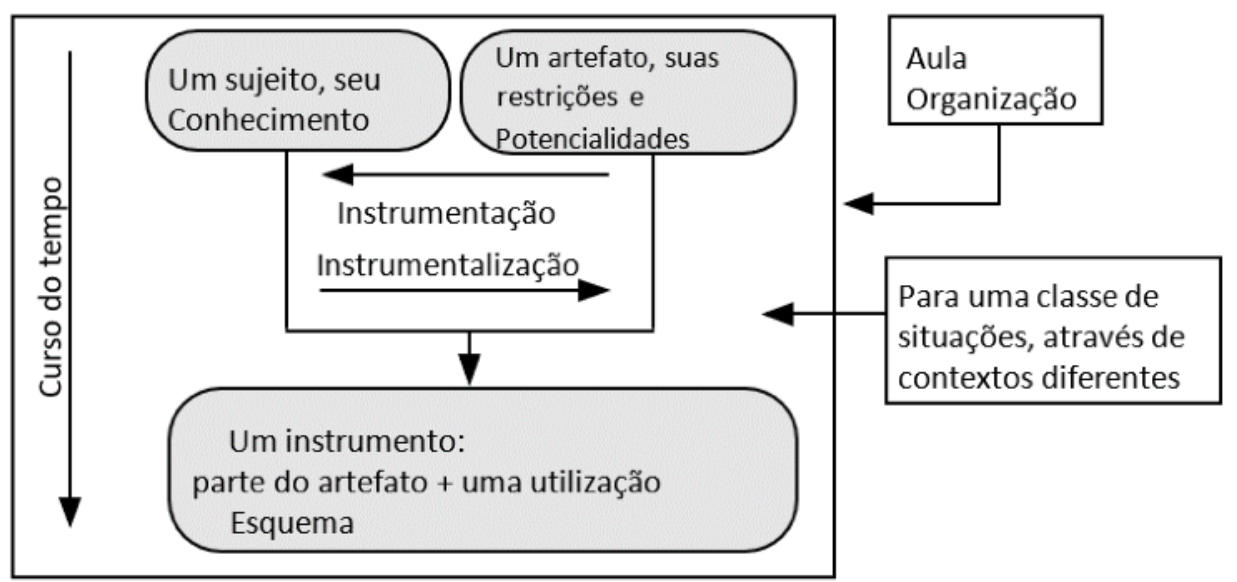

Fonte: Trouche e Maschietto (2009, p. 37)

Para exemplificar este processo (figura 1 e 2), mostra-se a produção de uma tarefa no GeoGebra 3D: a construção do cilindro circular de revolução (figura 3b). Tem-se o licenciando em matemática (o sujeito), o GeoGebra 3D (o artefato), o cilindro circular de revolução (o objeto - figura 3b). Para criar a tarefa, faz-se a restrição do uso das ferramentas automáticas oferecidas pelo software, em consequência o sujeito deverá construí-lo a partir das propriedades do objeto (restrições impostas). Inicia uma das componentes do processo de gênese, um artefato com suas restrições e potencialidades (instrumentação - orientada para o sujeito). O sujeito, de posse de seu conhecimento prévio (perpendicularidade e paralelismo: entre retas e planos; retângulo; circunferência; ângulos; rotação; dentre outros conceitos 
elementares - figura 3a), faz sua construção respeitando os princípios da geometria dinâmica mantendo a estabilidade sob a ação do movimento.

Figura 3 - Cilindro circular de revolução construído no GeoGebra 3D.

(a)

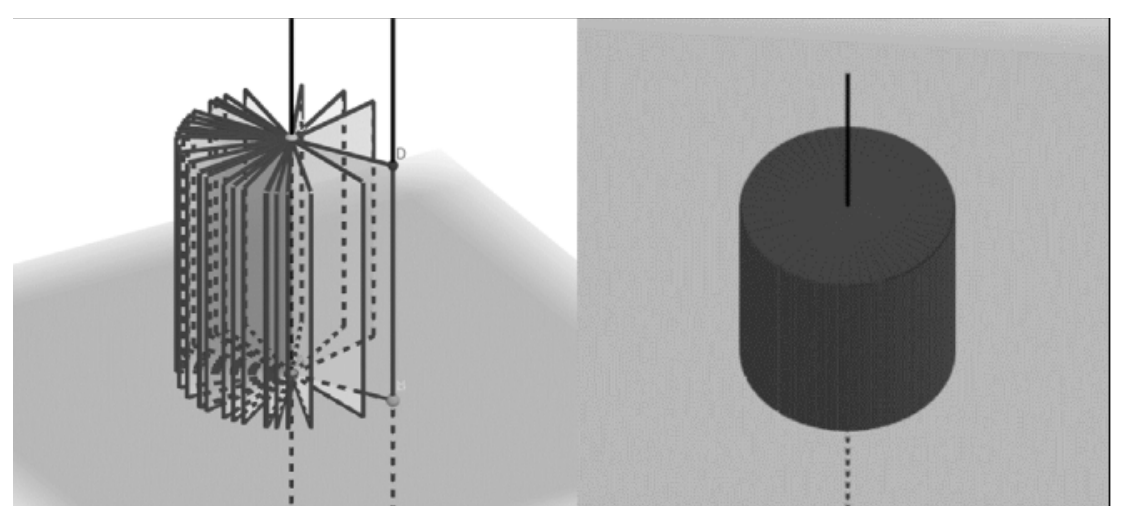

Fonte: Os autores.

(b)
Formam-se novos esquemas (GUIN e TROUCHE, 2002) e, de posse desses, o sujeito cria uma ferramenta automática para a construção do objeto cilindro, e considera-se, nessa situação, a instrumentalização (orientada para o artefato), na qual o sujeito personaliza o artefato de acordo com as necessidades. Neste exemplo tratado, simulou-se o processo de gênese instrumental pessoal e, para que ocorra a gênese instrumental profissional, o sujeito, quando docente, deverá incorporar essa TD em sala de aula, oportunizando aos seus alunos a construção do conceito de cilindro circular de revolução.

\subsection{O Mecanismo da Abstração Reflexionante}

Na obra de Piaget (1995), tem-se a apresentação de diferentes formas de abstração, dentre elas, a abstração empírica, a qual é definida como aquela que retira qualidades observáveis dos objetos antes da ação do sujeito sobre o objeto. Por exemplo, quando se apresenta uma construção pronta no GeoGebra 3D de um cilindro circular reto (figura 3b), o sujeito poderá retirar a cor, ou seja, apenas a qualidade do que foi observado, não gerando, portanto, conhecimento científico.

Na produção realizada pelo sujeito (figura 3a) na qual ele, de posse de seus conhecimentos prévios, faz um applet do cilindro levando a construção do conhecimento do conceito cilindro circular reto, trata-se de uma abstração reflexionante do tipo pseudo-empírica, pois o sujeito retira qualidades não do objeto, mas da sua própria ação sobre o objeto.

Neste exemplo se vê a importância da abstração reflexionante do tipo pseudo-empírica, sendo que o conceito formado de cilindro circular não está no objeto construído, mas no próprio sujeito. Becker (2014, p. 106) afirma que a abstração pseudo-empírica é diferente da abstração empírica em profundidade "porque por ela o sujeito retira qualidades, não de objetos, ou de ações observáveis, mas das coordenações das ações que, por se realizarem internamente ao sujeito, não são observáveis". A abstração pseudo-empírica é um meio para se 
chegar à abstração reflexionante do tipo refletida, e nesta direção o GeoGebra 3D possibilita ao sujeito ter uma abstração refletida, uma abstração reflexionante com tomada de consciência.

Para clarear esta afirmação anterior, analisam-se os desdobramentos que a produção do cilindro circular reto (figura 3a) pode fornecer ao sujeito. Ao movimentar o applet, o sujeito poderá começar a observar e retirar características das suas ações, levando-o a conjecturar que qualquer cilindro circular reto poderá ser obtido pela rotação de um retângulo em torno de uma reta que contenha um de seus lados, e que, o outro lado deste retângulo, constitui-se do raio do círculo da base desse cilindro. Considera-se, nesse contexto, que o sujeito teve uma abstração refletida, reflexionante com tomada de consciência, pois generalizou para os cilindros circulares retos. Desta conjectura forma-se o conhecimento científico matemático, a partir da qual o sujeito generaliza para o infinito, para todos os cilindros circulares retos.

Diversos estudos têm sido feitos em Educação Matemática utilizando-se do mecanismo da abstração reflexionante e da TD. Dentre estes estudos cita-se o trabalho de Bona, Fagundes e Basso (2012), os quais utilizaram como ambiente de aprendizagem para alunos do segundo ano do ensino médio o Facebook, como uma maneira de aprender a aprender matemática. Silva, Barone e Basso (2014) elaboraram um trabalho com alunos da graduação e com professores de matemática utilizando-se do GeoGebra para construção de conhecimento matemático envolvendo as Cadeias de Markov. Também se destaca o trabalho de Backendorf e Basso (2018) expondo uma pesquisa com alunos do curso superior, que tratou da construção do conceito da integral dupla por meio do GeoGebra. E, por fim, Notare e Basso (2018) trazendo uma discussão a partir de uma pesquisa com professores em formação, sobre as contribuições que o GeoGebra pode proporcionar em relação a problemas de geometria, cujos problemas necessitam de argumentação e prova. As referidas pesquisas contribuíram para o estudo em questão, pois mostraram como a TD pode colaborar para o ensino e aprendizagem da matemática em diversos níveis de ensino, além de se utilizarem do mecanismo da abstração reflexionante para compreender a construção de conhecimento do sujeito.

\subsection{Abstração Refletida no Processo de Gênese Instrumental}

Iniciou-se esse quadro teórico expondo o processo de gênese instrumental (RABARDEL, 1995) e, a seguir, o mecanismo da abstração reflexionante (PIAGET, 1995). Nesta subseção, procurar-se-á aproximar essas duas teorias, destacando-se as características do ambiente GeoGebra 3D para esclarecer como se propõe essa conexão.

O GeoGebra 3D vem de uma família de ambientes de geometria dinâmica (DGE) tendo três características: dependência funcional geométrica; variação dinâmica para destacar a invariância geométrica; diferenças entre o ambiente dinâmico do GeoGebra 3D e o estático do lápis e papel - consideradas fundamentais para a incorporação tecnológica do licenciando em matemática.

Para compreender o objeto de estudo, criou-se um modelo (figura 4), baseado no modelo (figura 1) de Rabardel (1995) e no modelo (figura 2) de Maschietto e Trouche (2009). Um modelo, segundo Curth (2015), pode ser a representação abstrata de um processo por meio de 
palavras simples, ideias ou esquemas. Procurou-se criar, então, um modelo simplificado (figura 4) utilizando palavras as quais caracterizassem cada componente do processo.

Figura 4 - Abstração refletida no processo de gênese instrumental

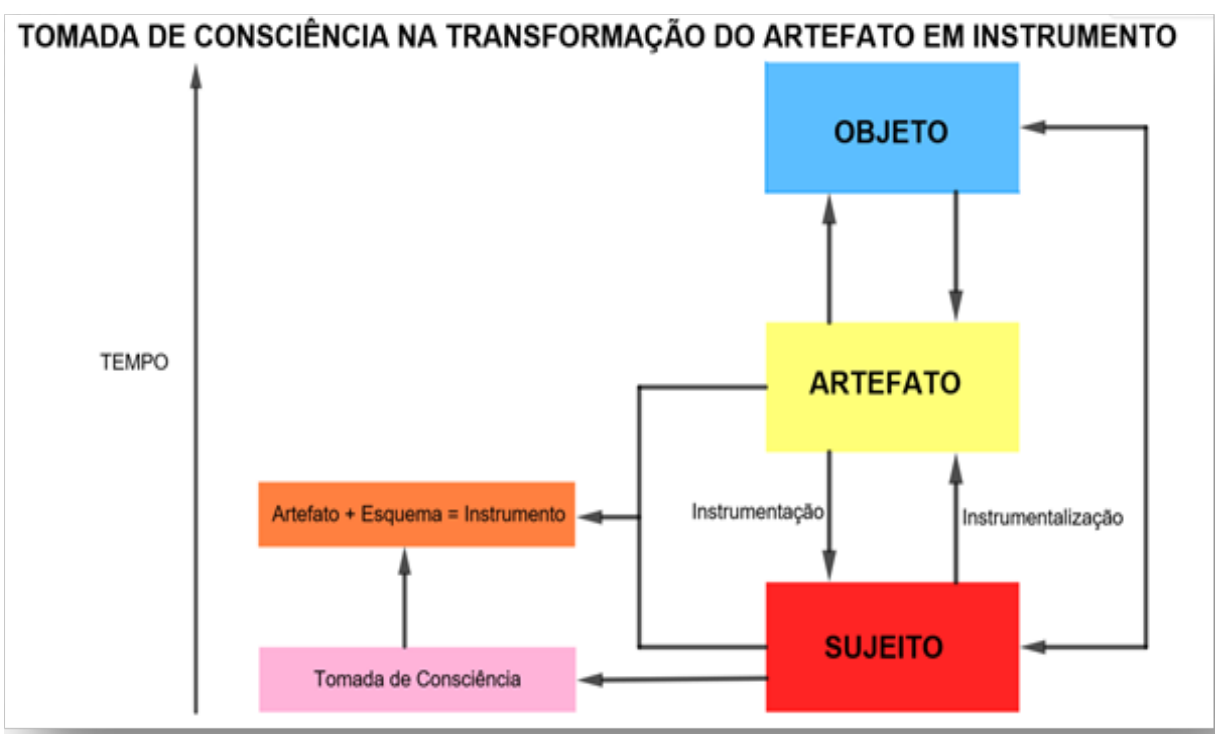

Fonte: Os autores.

A gênese instrumental foi representada por: um sujeito (um licenciando e seu conhecimento), um artefato (o GeoGebra com suas potencialidades e restrições), um instrumento (o artefato ou parte dele, acrescido dos esquemas do sujeito), um objeto (uma tarefa de geometria). Neste contexto formam-se os dois componentes da gênese instrumental: a instrumentação (orientada para o sujeito) e a instrumentalização (orientada para o artefato). O sujeito, ao tomar consciência de sua instrumentação, da transformação do artefato em instrumento (artefato mais os esquemas formados pelo sujeito), tem uma abstração refletida, retirando qualidades das coordenações das suas ações. Uma abstração refletida é uma abstração reflexionante com tomada de consciência. Nesta situação tem-se uma abstração refletida sobre o processo de gênese instrumental no curso do tempo (figura 4).

Comparando o modelo de Maschietto e Trouche (2009) com este modelo (figura 4), observa-se que foi acrescentado o mecanismo da abstração reflexionante, uma abstração refletida com a tomada de consciência, no processo de gênese instrumental, se criando, portanto, uma conexão entre estas duas teorias. O modelo (figura 4) segue a ideia de Curth (2015), servindo para analisar, descrever, explicar e simular como funciona este processo. Propõe-se que, quando o sujeito tomar consciência de que transformou o artefato em instrumento, ele terá realizado abstração refletida sobre sua apropriação tecnológica, sobre suas próprias ações, em relação às três características do GeoGebra 3D mencionadas anteriormente. Por meio desta apropriação ele conseguirá inserir na sua vida profissional, podendo-se entender que ocorreu a gênese instrumental profissional. Considera-se que ocorrerá a gênese profissional quando o sujeito tomar consciência de sua própria instrumentação em relação às características elencadas anteriormente do GeoGebra 3D e, assim, incorporar na sua atuação docente. 


\section{Objetivos}

Neste estudo investiga-se, na formação inicial de professor de matemática, a apropriação do GeoGebra 3D na construção de conhecimento geométrico espacial. Nesta apropriação da TD, busca-se identificar uma conexão entre a Abstração Refletida e o processo de Gênese Instrumental do sujeito, quando submetido a uma sequência de tarefas: quando usuário do ambiente 3D e na simulação da função de professor neste mesmo ambiente.

Elencam-se como objetivos específicos: identificar processos de gênese instrumental pessoal e profissional do licenciando a partir da observação de suas condutas cognitivas frente à construção de applet e figuras geométricas no GeoGebra 3D; discutir sobre a importância de esse professor em formação ter contato com esse tipo de tecnologia para o ensino e aprendizagem da matemática.

\section{Método}

Utilizou-se uma metodologia qualitativa e exploratória (Flick, 2009) sob a forma de estudo de caso (Ponte, 2006), com aproximação ao sujeito em seu ambiente natural, no laboratório de informática da instituição de ensino na qual ele estava inserido.

Para dar conta do estudo, traçou-se o curso descrito na figura 5.

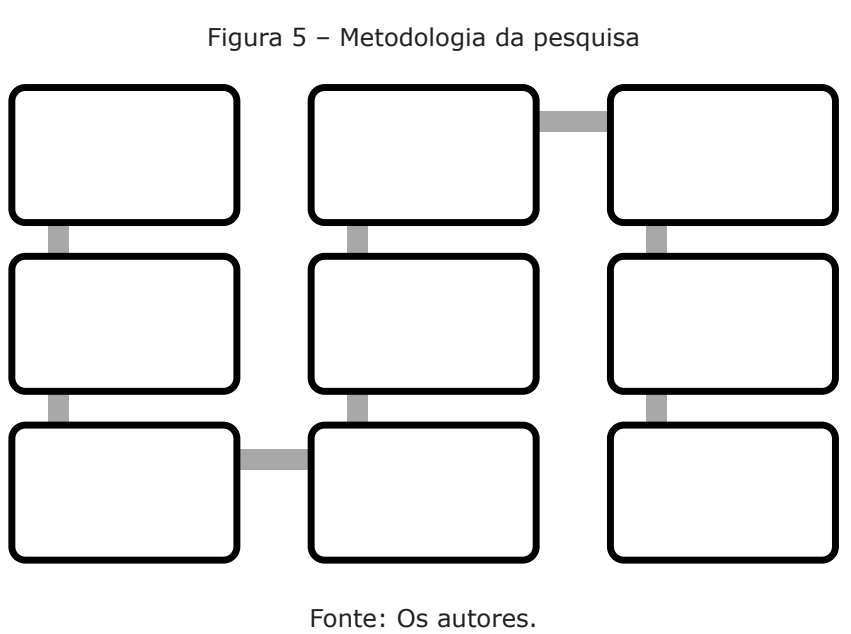

O estudo foi realizado em duas etapas, com o intuito de na primeira, observar a conduta cognitiva quanto à gênese pessoal; e, na segunda, quanto à gênese profissional. A primeira etapa foi constituída de cinco oficinas instrumentadas, na disciplina de Tecnologias Digitais no Ensino da Matemática (TDEM), nas quais o estudante foi submetido às tarefas no ambiente 3D sobre geometria espacial. Cada oficina, com exceção da primeira, a qual tinha seis tarefas, foi formada de cinco tarefas nas quais o estudante deveria construir representações dinâmicas, procurando se apoiar em relações matemáticas e nos princípios da geometria dinâmica (figura 6). A sequência de tarefas compôs-se de uma parte inicial, a qual exibia ideias sobre a geometria, figuras, conceitos ou fatos para uma breve contextualização, direcionando às construções no GeoGebra 3D. 
Figura 6 - Exemplo de tarefa

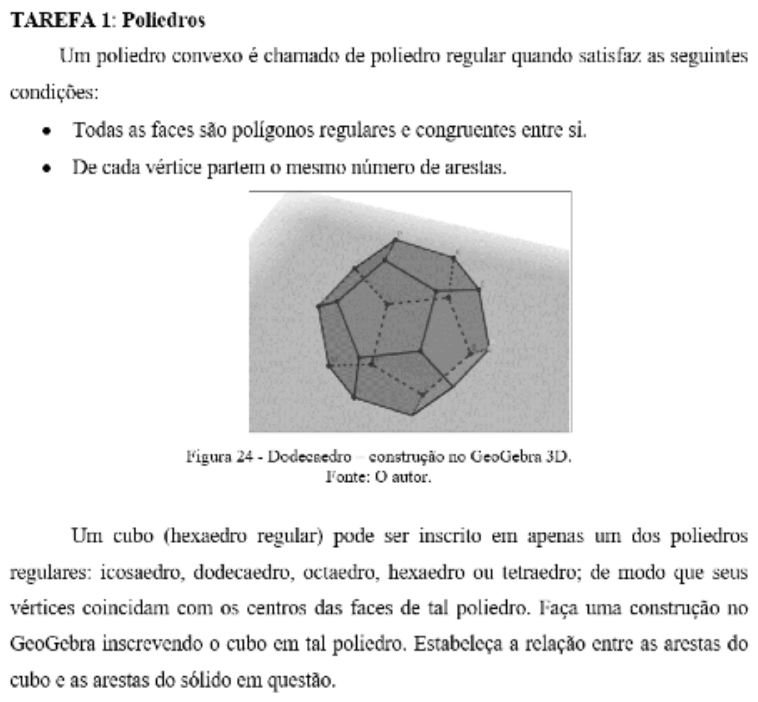

Fonte: Os autores.

Na primeira oficina, a primeira tarefa se referiu à exploração mais livre com orientações do pesquisador. A partir da segunda tarefa o estudante teve que produzir no GeoGebra 3D, com a mínima intervenção do pesquisador, sem usar comandos automáticos do software.

Na segunda etapa, o estudante participou de uma simulação de atividade docente, como professor, utilizando o mesmo ambiente 3D, tratando de geometria plana e espacial. A oficina foi ofertada para professores no mesmo laboratório das atividades executadas na primeira etapa. Os ouvintes não fizeram parte da análise de dados, visto que somente o licenciando estava sendo analisado.

As atividades foram individuais, com exceção da oficina de simulação de atividade docente, na qual foram formadas duplas, apenas para que cada estudante auxiliasse no manuseio do computador, isto é, enquanto um era o licenciando formador o outro era somente o auxiliar.

Para responder ao problema de pesquisa e contribuir no processo de análise dos dados, aplicou-se como instrumentos de produção de dados: vídeo (oficina instrumentada - 5 encontros (3h30min cada - disciplina de TDEM); protocolo de construção das atividades no GeoGebra 3D; entrevista - formulário Google docs; entrevista com aproximação ao sujeito sendo inspirada no método clínico; vídeo (oficina - simulação de atividade profissional - sujeito formador - 5 turnos de 3h cada); escrita do sujeito; observação da conduta cognitiva do sujeito in Ioco.

Apresentam-se a seguir os resultados e discussões desta intervenção.

\section{Resultados e Discussão}

Diante da quantidade de dados produzidos a partir dos instrumentos já descritos, resolveuse apresentar parte dos dados (de três tarefas e seus protocolos de construção; da escrita do estudante e do vídeo da primeira oficina instrumentada; da entrevista via Google docs e da 
entrevista inspirada no método clínico; do vídeo da primeira e da última oficina de simulação de atividade profissional) os quais evidenciaram que o licenciando realizou abstração refletida no processo de gênese instrumental.

A escolha do estudante Tiago ${ }^{2}$, com a idade de 19 anos, se deu pelo fato de que ele foi o primeiro a apresentar uma conduta corroborando com o modelo proposto (figura 4). Considerou-se um caso exemplar, sendo que os demais casos da turma estão sendo analisados separadamente, buscando evidências para comprovar o modelo. Pondera-se que, de acordo com o modelo, o processo ocorre num período, sendo que cada sujeito poderá apresentar evidências em tempos diferentes.

Neste estudo não se está pensando em generalizar para a turma em questão, visto que, segundo Ponte (2006, p. 15), não faz sentido "formular conclusões sob a forma de proposições gerais. Poderá haver, isso sim, a formulação de hipóteses de trabalho a testar em outras investigações". Considera-se, portanto, que "outras investigações" neste contexto são as "condutas cognitivas dos outros estudantes" da turma em que Tiago estava inserido.

\subsection{Análise das Tarefas}

Analisaram-se inicialmente as resoluções das tarefas por meio de suas construções e dos seus protocolos, observando as características da DGE já mencionadas anteriormente na seção 2.3 .

Da primeira oficina foram analisadas as tarefas de número dois, três e seis. A segunda tarefa (figura 7) apresenta o tema de posição entre as retas no espaço, e Tiago mostrou habilidade para construir, cuja habilidade se evidenciou na forma como os objetos foram criados.

Figura 7 - Tarefa 2 (posição de retas no espaço)

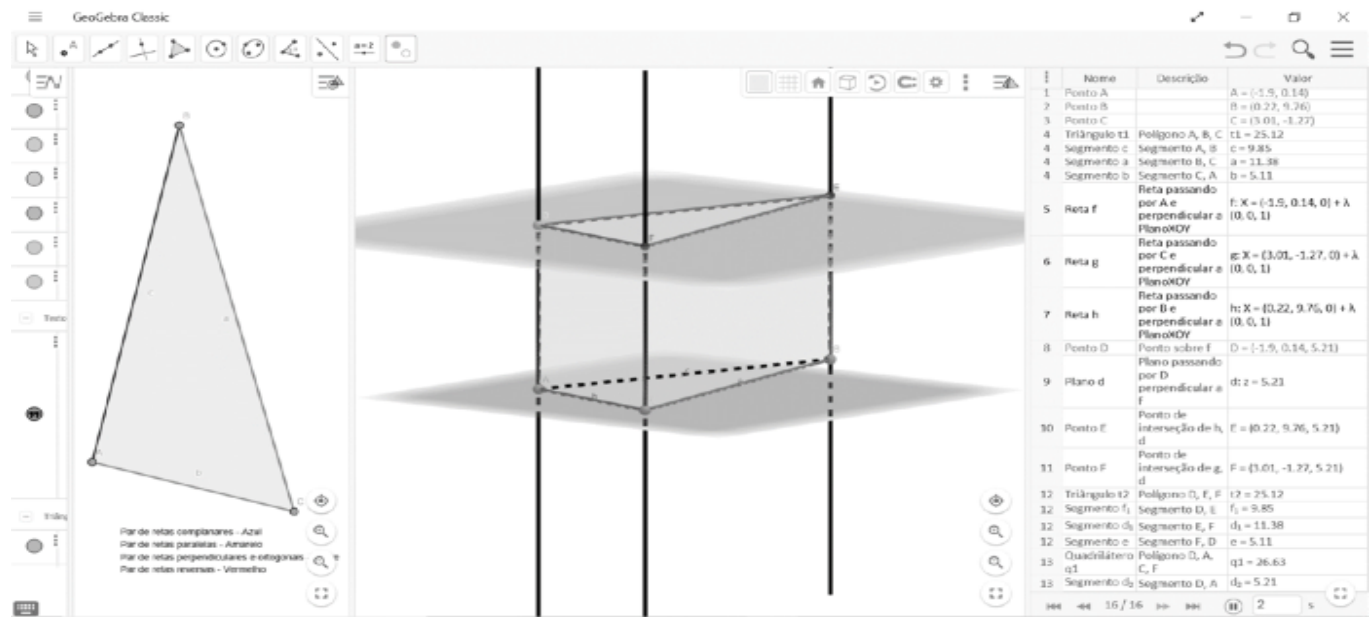

Fonte: Os autores.

2 Nome fictício. 
Inicialmente criou três pontos distintos e não colineares, A, B e C, a partir dos quais construiu um triângulo para a base de seu prisma. Em seguida traçou retas perpendiculares ao plano, passando pelos pontos A, B e C. Marcou o ponto D em uma das retas e criou um plano $d$ paralelo à base do prisma. Achou os pontos $\mathrm{E}$ e $\mathrm{F}$ de interseção das retas com o plano $d$. Escondeu as retas suportes, construiu os polígonos constituindo a área lateral do prisma e indicou corretamente com cores os segmentos de retas (arestas do prisma) destacando suas posições.

Tiago forneceu indícios de que planejava suas construções antes de executar, pois não se encontrou nenhum erro na construção, além de ela (a construção) manter a estabilidade sob a ação de movimentos. Realizou-se a movimentação da construção e verificou-se que esta (a construção) manteve a estabilidade, não se deformando. Considerou-se que Tiago mostrou indicativos de que se apropriou do software, pois as duas primeiras tarefas foram executadas sem erro e apresentaram evidências de que ele planejou antes de construir, além de ter escondido os objetos que serviram de auxiliares para a construção.

Na terceira tarefa (figura 8), ele construiu primeiro o cubo por meio de suas propriedades: retas paralelas, perpendiculares, planos paralelos, pontos de interseção entre as retas e o plano, polígonos para as faces. Inicialmente ele se utilizou de duas esferas, uma com centro em A passando por B, e outra com centro em B passando por A. O uso da esfera foi feito, segundo Tiago, valendo-se da ideia de como ele sabia construir um quadrado utilizando duas circunferências, e como o cubo é figura espacial, então se utilizou da esfera.

Figura 8 - Tarefa 3 (posição entre planos)
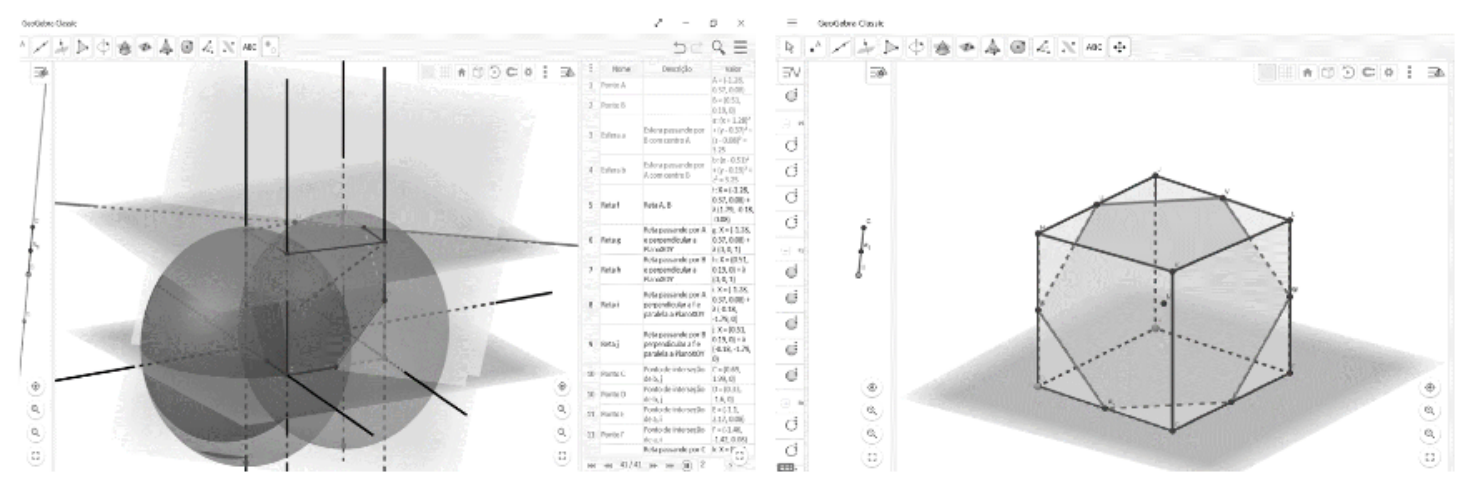

Fonte: Os autores.

A partir do cubo feito ele destacou a sua diagonal com seu ponto médio $M$, bem como o plano $d$ que passa pelos vértices $B, \mathrm{~J}$ e E. Em seguida criou um plano $n$ paralelo a $d$ passando por M. Indicando, logo após o polígono formado, ou seja, o hexágono regular. Tiago escondeu os objetos, deixando apenas o que aparece na figura a seguir (figura 8 à direita). Novamente a construção era estável e preservava as propriedades dos objetos geométricos construídos.

Na sexta tarefa (figura 9) ele poderia se utilizar de ferramentas automáticas do cubo visto que já tinha domínio da construção do cubo por meio de suas propriedades; no entanto, 
preferiu realizar sua construção utilizando sete esferas para a construção dos cubos. Notou-se a disponibilidade para trabalhar no GeoGebra 3D, procurando realizar a tarefa com qualidade. Nos seus arquivos verificou-se que Tiago mostrou corretamente as vistas da construção dada na tarefa.

Figura 9 - Tarefa 6 (vistas).

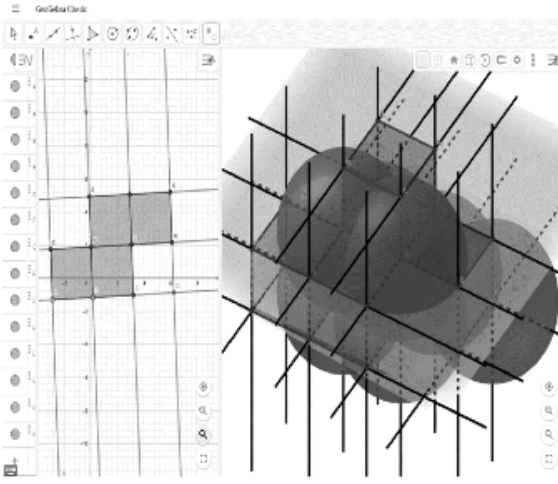

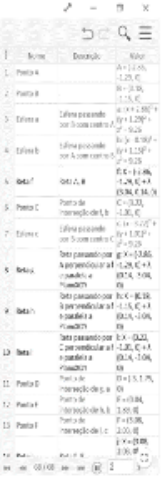

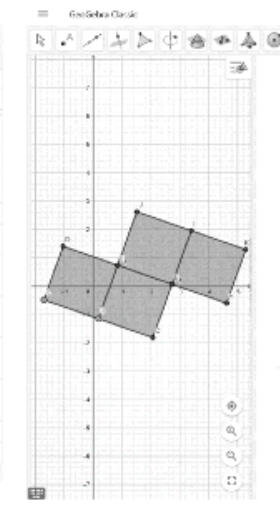

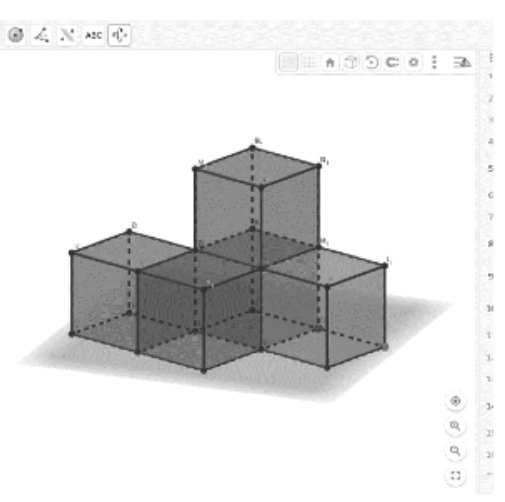

Fonte: Os autores.

Pode-se afirmar que Tiago, nesta primeira oficina instrumentada, desenvolveu habilidades em relação às características do software, evidenciados pelas construções com dependência funcional, estabilidade sob a ação de movimentos e pelas etapas construídas, mostrando fortes indícios de abstração refletida em relação à sua gênese pessoal.

\subsection{Análises das escritas}

A cada encontro o estudante deveria escrever as etapas de sua construção; suas ideias, seus pensamentos, suas emoções; as dúvidas e dificuldades que surgiram durante a construção; estratégias que usariam para resolver com lápis e papel, caso necessário.

O estudante Tiago fez uma escrita sobre a tarefa dois mostrando a facilidade na utilização do software, além de apresentar o conhecimento matemático procurando colocar retas que não coincidissem em duas categorias. Também mencionou a construção do prisma como sendo ações comuns para ele.

"Na tarefa 2, onde pedia-se que construísse um prisma de base triangular, destacando retas paralelas, ortogonais, reversas, perpendiculares e coplanares, não tive muitas dificuldades, pois a construção de retas ortogonais e fazer um plano paralelo a base do triângulo para formar o prisma já eram ações comuns para mim. Fora isso, tive que pensar um pouco em quais pares de segmentos separar, para não coincidir em duas categorias, assim como pensar em como os segmentos perpendiculares também são ortogonais (TIAGO, 2018)."

Notou-se que ele se utilizou de conhecimentos prévios para fazer a construção, e isso se observou quando ele afirmou que se utilizou dos mesmos pensamentos da aula anterior quando foi formar a figura "quadrado".

"Na tarefa 3, onde pedia-se que construísse um cubo, e reparasse na seção formada por determinada intersecção de plano e poliedro, tive um pouco de dificuldade ao pensar em que 
forma passar do quadrado para o cubo, mas em questâo de tempo, e utilizando os mesmos pensamentos que usei na aula anterior para formar o quadrado, consegui tranquilamente. Também perdi um pouco de tempo para achar as interseç̧ões com a secção do plano com o poliedro, mas identifiquei rapidamente o hexágono formado (TIAGO, 2018).

Em relação à sexta tarefa, ele também buscou seus conhecimentos prévios, quando afirmou que já tinha treino suficiente para a montagem de cubo. Observou-se que em apenas uma oficina ele já considerava que tinha apropriação das características do software, evidenciando uma abstração refletida sobre seu processo de gênese instrumental. Além disso, ele mencionou o uso de uma outra ferramenta, a qual não havia sido tratada na tarefa, apresentando-a para mostrar a vista do objeto 3D.

"Na sexta tarefa, que pedia para construirmos a figura que foi mostrada, como eu já tinha bastante treino em montagem de cubo, fiz de forma bastante rápida, interligando os quadrados das faces em retas perpendiculares, fazendo a intersecção entre as retas e entre reta e esfera, entre outros passos. Após finalizar, aprendi então como funcionava a ferramenta 'Vista para frente de' do GeoGebra, que nos permite ter uma visão da construção em determinado ângulo que se peça (TIAGO, 2018)."

De acordo com a escrita dele, ficou evidente em vários momentos a apropriação das características do GeoGebra 3D: o planejamento das construções; a utilização de estratégias anteriores (conhecimentos prévios em relação a construção de outro objeto matemático) para a nova construção; a exploração de novas ferramentas buscando a evolução dos esquemas (GUIN e TROUCHE, 2002).

\subsection{Observação da conduta cognitiva na oficina instrumentada}

Analisando-se o vídeo do primeiro encontro da primeira etapa, observou-se que Tiago construiu um cubo utilizando-se da ideia de como fazer um quadrado no plano, ou seja, para construir o quadrado ele se utilizou de duas circunferências, e no espaço, de duas esferas, buscando estabelecer o mesmo tamanho de três arestas que partem de um mesmo vértice. Nesse sentido, já se verificou que ele procurou construir suas tarefas observando as propriedades dos objetos matemáticos. No vídeo encontrou-se a conexão entre as atividades construídas e sua escrita, ou seja, verificou-se que sua construção e fala foram comprovadas na análise do vídeo.

Tiago resolveu corretamente a tarefa três, posição entre planos, e sua construção manteve a estabilidade sob a ação de movimentos.

O estudante chamou o pesquisador para explicar que o software fez algumas restrições em relação à interseção de objetos (restrições impostas pelo software levam à formação de novos esquemas) (GUIN e TROUCHE, 2002) e mostrou como conseguiu fazer as interseções, buscando outra forma de resolver o problema. Durante a oficina, ele se concentrou, pesquisou na web sobre conceitos matemáticos e, quando não conseguiu sozinho, buscou a ajuda do pesquisador na interpretação do enunciado da tarefa. Observou-se que na primeira oficina Tiago auxiliou os colegas, perguntando como eles fizeram; tirou dúvidas buscando identificar os 
erros nas construçőes. Fez indagações para eles levando-os a refletirem sobre as tarefas (evidências de gênese instrumental profissional).

Pela conduta cognitiva apresentada no vídeo, ponderou-se que Tiago tinha apropriação das características do software (gênese instrumental pessoal) e, a partir dos auxílios aos colegas, caracterizando a gênese instrumental profissional, além de apresentar indícios de ter realizado uma abstração refletida sobre o seu processo de gênese instrumental.

\subsection{Análise da entrevista via formulário}

A partir da entrevista via formulário, constatou-se que Tiago se considerava integrado tecnologicamente em sua vida pessoal, e, se estivesse formado, levaria a TD para a sala de aula. Afirmou que a TD é muito promissora em diversos aspectos dentro da sala de aula, mas se o professor não estiver "bem apropriado da tecnologia", uma "aula tradicional se sobrepõe. Isso porque sem um devido preparo do professor, pode acabar mais confundindo do que fazendo com que o aluno aprenda (TIAGO, 2018)."

Questionado sobre a inserção de TD em seu estágio de docência, ele apontou que era uma situação bem delicada, pois dependia da turma e da estrutura física da escola. Ele achava difícil de aplicar a tecnologia na escola na qual ele pretendia estagiar, porém tinha interesse em inseri-la. O estudante afirmou não ter medo de inserir a TD na prática docente, destacando que todo professor "deveria sentir é um sentido desafiador. Isso porque sabemos que a tecnologia ajuda bastante, e o medo deve ser convertido em coragem para explorar as tecnologias, apropriá-las e posteriormente integrar a tecnologia em sala de aula, com segurança de que tudo, ou quase tudo, ocorrerá de forma satisfatória" (TIAGO, 2018).

O estudante não tinha tecno-ansiedade, mostrava atitude positiva em relação à inserção dos computadores na sala de aula, sentia-se preparado, tinha confiança na utilização da TD.

Ele avaliou que um professor que não utilizava TD para ensinar matemática poderia ser um professor de atitude negativa em relação a ela, ou talvez "mais velho, que não tem a mínima intenção de mudar a forma que sempre deu aula, isso acontece bastante. Eu acho que a comodidade que essas pessoas estão, afeta isso de forma muito negativa, e que dessa forma eles nunca buscarão por mais conhecimento na área da tecnologia. São pessoas estagnadas ou sem a perspectiva de evolução dentro da área da educação (TIAGO, 2018)."

Disse que se apropriou do GeoGebra e que já usou a maioria das ferramentas, e as mais importantes. "Óbvio que se partirmos para questões muito específicas encontrarei dificuldades, mas com o leque de opções que já disponibilizo para realizar no software, considero que consigo sim, produzir muita coisa (TIAGO, 2018)".

Ele apresentou características do GeoGebra, tais como "criar, modelar e manipular livremente formas geométricas, além de estudo de funções, propriedades, (...) (TIAGO, 2018)".

Ao finalizar sua fala, apontou algumas dificuldades que considerava ao realizar as construções: "são no sentido de saber a ordem em que as coisas têm que ser construídas, para que um objeto dependa do outro, e assim formar o que se deseja. (...) figuras espaciais específicas, como um cone equilátero, por exemplo, onde uma parte da figura depende da outra, e não se pode utilizar medidas, e sim as propriedades (TIAGO, 2018)". Nessa fala 
verificou-se que ele tinha consciência da característica da dependência funcional, quando falou da ordem em que os objetos deveriam ser construídos.

\subsection{Observação da conduta cognitiva na simulação de atividade docente}

A organização das apresentações da oficina obedeceu aos seguintes critérios: formação de duplas para apresentar construções de geometria plana e espacial no GeoGebra 3D; explicação das funções das ferramentas; apresentação da construção mostrando todas as suas etapas.

A formação de dupla foi criada tão somente para que um aluno auxiliasse o outro na inserção de ferramentas, sendo que o apresentador era o responsável por mostrar como a construção deveria ser feita, além de explicar a função de cada ferramenta. Não se fez a análise da conduta da dupla de Tiago, visto que somente a conduta deste era o objeto de análise neste momento.

Tiago atuou como professor em duas oficinas - 20/10 e 27/11 -, além de, nas outras três, dar auxílio diretamente ao cursista em seu computador. Nesse primeiro dia de oficina de simulação de atividade docente (20/10/2018), o pesquisador iniciou apresentando o software, o site do geogebra.org e trabalhou construções. Após, Tiago e seu parceiro ficaram responsáveis de guiar os cursistas, em torno de $2 \mathrm{~h}$ de duração. Os demais alunos, os quais faziam parte da pesquisa, ficaram auxiliando os cursistas em seus computadores. Registra-se aqui que os estudantes já tinham participado de três oficinas instrumentadas (04, 11 e 18/10) anteriores ao primeiro encontro da oficina de simulação de atividade docente.

Neste momento tratar-se-á somente da análise da conduta de Tiago em relação ao auxílio prestado ao seu colega. Observou-se que Tiago auxiliou com competência, manipulando rapidamente as ferramentas, mostrando facilidade e tranquilidade. Não se limitou a manipular o computador, em diversos momentos procurou ajudar com explicações sobre as propriedades das figuras construídas. Mostrou que tinha conhecimento das versões do software e atalhos do teclado. Houve momentos em que ele questionou os cursistas sobre as propriedades das figuras e como poderia fazer demonstrações (prova). Mesmo atuando como auxiliar, ele explicou como fazer a construção bem como os conceitos matemáticos envolvidos. Enquanto os cursistas foram trabalhando, ele chamava seu colega e lhe dava instruções. Nessa primeira participação, Tiago trabalhou com figuras planas, tais como construção de triângulos equiláteros e quadrados, bem como a utilização do menu das transformações geométricas, sempre por meio das propriedades das figuras.

No dia 27/11/2018, último encontro da oficina de simulação de atividade docente, com os cinco encontros da oficina instrumentada já realizados, Tiago atuou como o apresentador principal (aproximadamente 1h30min), guiando as construções no software, enquanto seu colega atuava como auxiliar. Seu colega se limitou a manipular as ferramentas, não interferindo na apresentação de Tiago.

Nessa oficina ele trabalhou com sólidos (cubo e cilindro) inscritos e circunscritos à esfera. O estudante questionou, por exemplo, como circunscrever uma esfera a um cubo: "E agora como nós vamos fazer para uma esfera passar pelos vértices desse cubo? Alguém tem alguma ideia? 
(TIAGO, 2018)". Foi perguntando e destacando quais as relaçöes entre os elementos do cubo e da esfera, sugerindo estabelecer uma relação entre a aresta do cubo e o raio da esfera.

O pesquisador, à medida que Tiago ia apresentando, foi fazendo questionamentos, procurando verificar as apropriações em relação aos conhecimentos matemáticos e às características do software. Um dos objetivos foi provocar o aparecimento de situações as quais ele não tinha se preparado para responder, situações que o software proporcionou além do que tinha programado para trabalhar com os cursistas. Ele conseguiu responder corretamente aos questionamentos dos cursistas e do pesquisador.

Notou-se que Tiago, à medida que foi guiando a construção, também destacou restrições do software e apresentou formas de resolver essas situações de restrição. Faz-se aqui uma relação com o componente da gênese instrumental, a instrumentação orientada para o sujeito, a ação instrumental: a instrumentação "é relativa ao surgimento e evolução dos esquemas de um sujeito para a execução de uma determinada tarefa" (GUIN e TROUCHE, 2002, p. 205). Considera-se a evolução dos esquemas de Tiago, contornando as restrições do software e atingindo seu objetivo na construção do objeto matemático. Observa-se uma evolução dele em relação ao primeiro encontro da oficina na qual era auxiliar, no sentido de apropriação do software, mostrando apropriação dos princípios da DGE, além de apresentar evidências de ter realizado abstrações refletidas sobre essa apropriação.

\subsection{Análise da entrevista inspirada no método clínico}

No que segue, apresentam-se as falas mais evidentes a partir das quais concluiu-se que Tiago realizou abstrações refletidas sobre o seu processo de gênese instrumental, indicando a validação do modelo (figura 4) aplicado a este caso.

A entrevista, inspirada no método clínico, deu-se numa sala de filmagens da instituição $X$, sendo que nesta se encontrava apenas Tiago e o pesquisador. Ela foi filmada para melhor análise das falas dele e foi fundamentada nas questões tratadas na entrevista via formulário.

Tiago se considerava inserido tecnologicamente, tanto em conhecimento de hardwares, softwares, tais como planilha eletrônica; já fez curso de montagem de computadores, porém não quis seguir na área da computação. Seu conhecimento tecnológico foi adquirido por interesse pessoal e por necessidade.

Foi questionado sobre a inserção de TD na sala de aula: "Com certeza, a ideia seria sempre buscar esse tipo de inserção, acho isso muito válido. Mas, tem outros problemas nessa equação. Então, na medida do possível sim, porque por exemplo, para trabalhar com o GeoGebra, depende muito de estrutura. Porque uma atividade onde o professor está fazendo no GeoGebra e só mostrando para os alunos não difere tanto assim de uma aula em quadro. Então, assim, conforme for possível utilizar, eu tenho muito interesse sim, em utilizar isso (TIAGO, 2018)." Observou-se que Tiago gostaria de utilizar um ambiente no qual o aluno pudesse estar em ação, ou seja, trabalhando com o software e não um mero expectador. Ele seguiu a ideia de Piaget (1958), na qual a ação leva a construção do conhecimento. Ele destacou o uso da TD para aprendizagem e para a motivação do aluno em relação à matemática. Acrescentou que no GeoGebra, com uma prática boa do professor no sentido que 
não é só levar a TD para sala de aula, "é possível fazer os alunos pensarem muito (...) dependendo da idade, eles irão querer comparar resultados, caminhos diferentes, essa possibilidade de interação muito grande, assim, tanto entre o aluno e o objeto, tanto quanto entre os alunos, essa gama de possibilidades que se abre assim com o GeoGebra é muito, muito interessante para o ensino da matemática (TIAGO, 2018)."

Percebeu-se que o estudante tinha conhecimento da abertura que o software proporciona, ou seja, a utilização deste faz com que o aluno não fique limitado à atividade proposta pelo professor. Cria-se, ao utilizar o GeoGebra, uma oportunidade de o aluno ir além do que o professor propõe, gerando no aluno a liberdade de aprender.

Foi questionado sobre as dificuldades encontradas em relação às atividades. De acordo com Tiago, uma das dificuldades foi em relação à interpretação do que deveria ser realizado. No começo ele não via muitos caminhos, porque não conhecia muito bem as ferramentas, depois que ele já pode construir um triângulo por meio das propriedades, observou que poderia levar essa ideia para construir outras figuras, e ir usando rotações, reflexões, translações, dentre outras ferramentas. A partir daí ele teve mais opções e começou a arquitetar como iria construir com as ferramentas que possuía; ele enfatizou que primeiro tinha que assimilar o que precisaria fazer.

Nesta fala inferiu-se que ele já se apropriou das características de dependência funcional e estabilidade sob a ação de movimentos, pois afirmou que poderia se utilizar da ideia de construir um triângulo para construir outras figuras.

Também destacou as restrições que o software apresentou quando foi trabalhar com a geometria espacial, o que o software deixava ou não fazer, sendo que teve que achar uma forma de ultrapassar essa restrição e fazer a construção. Percebe-se aqui um dos componentes da gênese instrumental, a instrumentação orientada para o sujeito (GUIN e TROUCHE, 2002).

Falou que teve que relembrar propriedades e citou o conceito do ângulo poliédrico, o qual não lembrava, tendo que resgatar esse conhecimento para poder fazer a sua construção no GeoGebra 3D. No início das tarefas ele fazia mais por tentativa e erro; no entanto, sabia que dava para fazer daquele jeito, ia construindo e vendo onde iria parar, posteriormente já fazia um planejamento prévio até certa etapa, além de fazer experimentações.

Comparou-se duas construções: uma de um quadrado feita com compasso, régua e esquadro (físicos) num ambiente lápis e papel e outra, da mesma figura, no GeoGebra. Solicitou-se a ele que destacasse se existia diferença entre essas construções e, caso houvesse, se ele poderia apontar quais. Ele apontou como diferença a precisão na construção no GeoGebra, a posição das figuras, que no papel ficaria "rígida", o que se entende como fixa, e que o GeoGebra tem a movimentação que ajuda a mostrar a invariância. Notou-se que ele mostrou a característica da DGE, a estabilidade sob a ação de movimentos.

Também falou das leituras que fez sobre a utilização do GeoGebra, as quais apoiaram a utilização desse software, facilitado a organização lógica dos pensamentos, o pensar; destacou a dependência funcional, contribuindo para a construção do conhecimento. 
Quanto à apropriação do GeoGebra 3D ele afirmou que já tinha conhecimento suficiente para dizer que já se apropriou, sendo que conseguiria relacionar os conhecimentos matemáticos com as possibilidades criadas pelo software.

Diante de tais considerações feitas por Tiago, identificou-se indícios de que ele teve consciência da sua gênese pessoal e profissional e, nesse sentido, pode-se concluir que devido a essa tomada de consciência das características do software ele manifestou essa posição a favor da inserção do GeoGebra em sala de aula. Considerou-se, portanto, que o modelo (figura 4) reflete que o sujeito irá utilizar o GeoGebra 3D em sala de aula (gênese instrumental profissional) se realizar abstrações refletidas sobre as características do ambiente, ou seja, abstrações refletidas sobre sua gênese instrumental.

\section{Considerações Finais}

A presente pesquisa seguiu princípios éticos considerando: a aproximação do sujeito em seu ambiente natural; a aplicação do termo de consentimento livre e esclarecido; a aprovação do projeto sob o número 83783818.4.0000.8049 no Comitê de Ética em Pesquisa com Seres Humanos (CEPSH).

Neste estudo, buscaram-se evidências para comprovar o modelo (figura 4) proposto sobre a abstração refletida no processo de gênese instrumental. No artigo apresentam-se as análises preliminares de um estudo de caso a partir do qual concluiu-se que ocorreram abstrações refletidas neste processo. Utilizou-se de vários instrumentos para a produção dos dados, fazendo uma triangulação destes, observando o sujeito sob vários ângulos, investigando como ocorre esta abstração refletida no processo de gênese instrumental

Finalmente destaca-se que este trabalho é parte de um projeto maior que busca em outros casos, na mesma turma de estudantes, as mesmas evidências, ou até mesmo outras que poderão surgir corroborando com o modelo (figura 4) sobre "Abstração Refletida no Processo de Gênese Instrumental".

\section{Referências}

ABAR, Celina Aparecida A. P.. Tecnologias Digitais e Educação Matemática. In: CONGRESSO URUGUAYO DE EDUCACIÓN MATEMÁTICA, 7., 2017, Montevideo. Actas. Montevideo: Curem, 2017. p. 33 - 41. Disponível em: <http://semur.edu.uy/curem/actas/pdf/31.pdf>. Acesso em: 25 nov. 2017.

ALQAHTANI, Muteb M.; POWELL, Arthur B.. Mediational activities in a dynamic geometry environment and teachers' specialized content knowledge. The Journal of Mathematical Behavior, [s.I.], v. 48, p.77-94, dez. 2017.

BECKER, Fernando. Abstração pseudo-empírica e reflexionante: significado epistemológico e educacional. Schéme: Revista Eletrônica de Psicologia e Epistemologia Genética, Marília, v. 6, p.104-128, 10 dez. 2014. Disponível em: <http://www2.marilia.unesp.br/revistas/index.php/scheme/article/view/4276>. Acesso em: 01 mar. 2019.

CURTH, Mónica de Torres. Los reyes de la pasarela, modelos matemáticos en las ciencias. Ciudad Autónoma de Buenos Aires: Fundación de Historia Natural Félix de Azara, 2015. 
DRIJVERS, Paul; TROUCHE, LuC. From artifacts to instruments: a theoretical framework behind the orchestra metaphor. K. Heid \& G. Blume Research on Technology and the Teaching and Learning of Mathematics, Information Age, pp.363-392, 2008.

FLICK, Uve. Desenho da Pesquisa Qualitativa. Porto Alegre: Artmed, 2009.

GUIN, Dominique; TROUCHE, Luc. Mastering by the teacher of the instrumental genesis in CAS environments: necessity of instrumental orchestrations. Zentralblatt Für Didaktik der Mathematik, [s.l.], v. 34 , n. 5, p.204-211, out. 2002.

HASPEKIAN, Mariam. Teachers' Instrumental Geneses When Integrating Spreadsheet Software. The Mathematics Teacher in the Digital Era, [s.I.], p.241-275, 30 set. 2013.

MASCHIETTO, Michela; TROUCHE, Luc. Mathematics learning and tools from theoretical, historical and practical points of view: the productive notion of mathematics laboratories. Zdm, [s.I.], v. 42, n. 1 , p.33-47, 29 set. 2009.

NOTARE, Marcia Rodrigues; BASSO, Marcus. Argumentação e Prova Matemática com Geometria Dinâmica. Revista Novas Tecnologias na Educação: RENOTE, Porto Alegre, v. 16, n. 1, p.1-10, 2018.Disponível em: <https://seer.ufrgs.br/renote/article/view/86021>. Acesso em: 03 set. 2018.

PIAGET, Jean. Abstração Reflexionante: Relações Lógico-aritméticas e Ordem das Relações Espaciais. Tradução: Fernando Becker e Petronilha Beatriz Gonçalves da Silva Porto Alegre: Artmed, 1995.

PIAGET, Jean. Psicologia da Inteligência. Rio de Janeiro: Fundo de Cultura, 1958.

PONTE, João Pedro da. Estudos de caso em educação matemática. Bolema, Rio Claro, v. 19, n. 25, p.105-132, 2006. Disponível em: <http://www.periodicos.rc.biblioteca.unesp.br/index.php/bolema/article/ view/1880>. Acesso em: 15 mai. 2018.

RABARDEL, P.. Les hommes et les technologies: une approche cognitive des instruments contemporains. Paris: Armand Colin, 1995. Disponível em: <https://hal.archivesouvertes.fr/file/index/docid/1017462/ filename/Hommes_et_technol ogie_Rabardel1995. pdf>. Acesso em: 27 mar. 2017.

ROCK, Ana Isabel Sacristán. Aprender Matemáticas en la Era Digital. In: Avance y Perspectiva. México, Cinvestav, 2017. V.2. n.4.

RUIZ-LÓPEZ, Natalia. The instrumental genesis process in future primary teachers using Dynamic Geometry Software. International Journal of Mathematical Education in Science and Technology, [s.I.], v. 49, n. 4, p.481-500, 23 out. 2017.

TROUCHE, Luc. New technological environments: new constraints, new opportunities for the teacher. International Journal of Computer Algebra in Mathematics Education, Waynesville, v. 3, n. 7, p.167-180, 2000. Disponível em: <https://hal.archives-ouvertes.fr/hal-01552317>. Acesso em: 03 fev. 2013.

TROUCHE, Luc. From artifact to instrument: mathematics teaching mediated by symbolic calculators. Interacting with Computers, [s.I.], v. 15, n. 6, p.783-800, dez. 2003.

VERGNAUD, G. At the heart of the learning, the conceptualization. Proceedings of the summer school in didactics of mathematics. IREM, Université Clermont Ferrand 2, p.174-185, 1996.

Recebido em julho de 2019.

Aprovado para publicação em fevereiro de 2020.

\section{Margarete Farias Medeiros}

Professora do Instituto Federal catarinense Campus Avançado Sombrio

Doutoranda do PPGIE UFRGS - margarete.medeiros@ifc.edu.br.

\section{Marcus Vinicius de Azevedo Basso}


Professor titular do Instituto de Matemática e Estatistica da UFRGS. Docente e orientador nos Programas de Pós-graduação em Ensino de Matemática e Informática na Educação da UFRGS. Atualmente coordena o Centro de Formação Continuada de Professores (FORPROF) da UFRGS e o Programa de Pós-graduação em Ensino de Matemática, mbasso@ufrgs.br. 